\title{
Study of Heavy Elements and Radioactivity Concentrations in Some Eye Cosmetics Commonly Used in Arabic Regions
}

\author{
M. M. Sherif, M. Orabi, and O. R. Abdurahem
}

\begin{abstract}
Thirteen samples of eye cosmetics including five samples of artificial eye cosmetics and eight samples of traditional eyeliner (kohl) were collected from various Arabic markets, and analyzed using inductively coupled plasma-optical emission spectrometer (ICP-OES) to assess concentrations of the most toxic elements (arsenic (As), cadmium $(\mathrm{Cd})$, mercury $(\mathrm{Hg})$ and lead $(\mathrm{Pb})$ ), and high purity germanium detector (HPGe) to determine radioactivity concentrations of the natural radionuclides ${ }^{238} \mathrm{U},{ }^{235} \mathrm{U},{ }^{226} \mathrm{Ra},{ }^{232} \mathrm{Th}$ and ${ }^{40} \mathrm{~K}$. The average concentrations of the elements $\mathrm{As}, \mathrm{Cd}, \mathrm{Hg}$ and $\mathrm{Pb}$ are a bit high in some samples in a way that they might cause some harm to human health, while the average values of the activity concentrations for ${ }^{238} \mathrm{U},{ }^{235} \mathrm{U},{ }^{226} \mathrm{Ra},{ }^{232} \mathrm{Th}$ and ${ }^{40} \mathrm{~K}$ are not that high. Annual absorbed amounts of heavy elements from daily applied kohl were calculated based on roughly assumption that about $50 \%$ of the applied kohl is absorbed into the body. An appropriate simulation has been done for the eye using the MCNP code to estimate the dose rate of the lens of the eye as a result of using contaminated kohl.
\end{abstract}

Index Terms-Cosmetics, kohl, MCNP code, radioactivity concentrations, heavy elements concentrations.

\section{INTRODUCTION}

This work represents a part of our study of heavy elements and radioactivity concentrations in 40 samples of cosmetics. In this paper we only present the results of eye cosmetics which include artificial eye cosmetics (eye shadow, mascara and eyeliner) and traditional eyeliner (kohl). Kohl is the most traditional cosmetic used in the Arabic regions. It is often deliberately placed inside the eye, on the conjunctive surface, because of the Arabs thoughts about its benefits: wide eye, purifies it from dust and impurities, and protects it from hot sunshine. Kohl is sold in markets as powders and stones like in Fig. 1.

Heavy elements can harm human health, because after absorbing them, they accumulate in the internal organs of the body such as bone, liver, kidneys, pancreas and lungs, and hence cause damage over time. The most toxic elements are $\mathrm{As}, \mathrm{Cd}, \mathrm{Hg}$ and $\mathrm{Pb}$ [1]. The allowable level of lead in cosmetics is $10 \mathrm{ppm}$ as given in Canadian health [1] and 20 ppm in US-FDA [2], while the allowable levels of As, $\mathrm{Hg}$ and $\mathrm{Cd}$ are 3 ppm in Canadian health [1], and 5 ppm, 1 ppm and 5 ppm respectively in US-FDA [2]. The effect of radiation on the eye is particularly in cataracts, which may happen if the

Manuscript received February 23, 2014; revised May 19, 2014

The authors are with Cairo University, Cairo, Giza 12613, Egypt (e-mail: mmsherif@enu.eg, asiza14@yahoo.com). dose exceeds $15 \mathrm{mSv}$ [3].

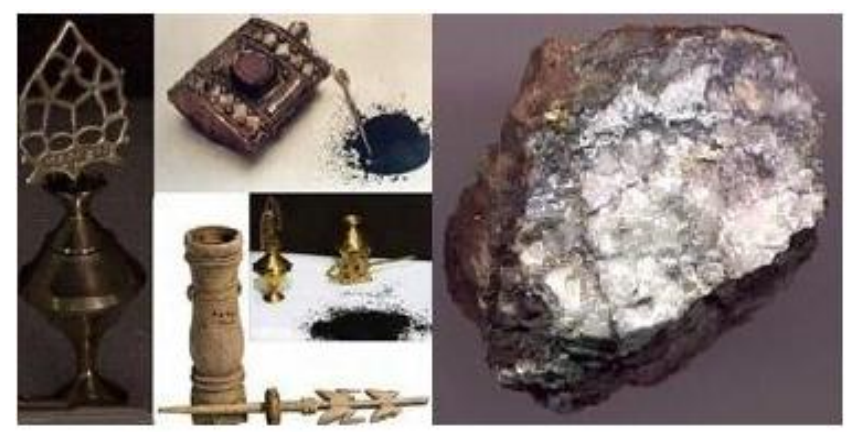

Fig. 1. Powdered kohl and kohl stone.

\section{EXPERIMENTAL WORK}

\section{A. Samples Collection}

The thirteen samples were purchased from various markets in Libya, Egypt and KSA. These samples include one eyeliner, one mascara, three eye shadows, one kohl powder and seven kohl stones.

\section{B. Elemental Analysis}

Sample digestion: A $0.15 \mathrm{~g}$ of each sample, $7 \mathrm{ml}$ high purity $\mathrm{HNO}_{3}$ and $2 \mathrm{ml}$ high purity $\mathrm{HF}$ are added to a microwave vessel and the mixture is heated to $130^{\circ} \mathrm{C}$ for more than $15 \mathrm{~min}$. Then, this mixture is held at $130^{\circ} \mathrm{C}$ for three minutes before the temperature is ramped to $200^{\circ} \mathrm{C}$ for more than $15 \mathrm{~min}$ and held at $200^{\circ} \mathrm{C}$ for $30 \mathrm{~min}$. After that, $30 \mathrm{ml}$ of $4 \%$ high purity $\mathrm{H}_{3} \mathrm{BO}_{3}$ is added to the vessel for neutralizing the $\mathrm{HF}$, then the mixture is heated again in the microwave to $170^{\circ} \mathrm{C}$ over $15 \mathrm{~min}$ and held for $10 \mathrm{~min}$ at $170^{\circ} \mathrm{C}$. The mixture is then diluted to $50 \mathrm{ml}$ using distilled $\mathrm{H}_{2} \mathrm{O}$.

The samples are analyzed using the Thermo scientific iCap 7000 series ICP-OES spectrometer in Laboratories Compound of Desert Research Center of Egyptian Ministry of Agriculture and Land Reclamation.

\section{Radioactivity Measurements}

Radioactivity measurements are applied only on samples of kohl stones due to the lack of the suitable standards for other samples. Using a standard sample is necessary to make the efficiency calibration for HPGe detector.

Sample preparation: Kohl stone is crushed to a powder form which is then collected through a $0.85 \mathrm{~mm}$ mesh sieve. After that, the sample is placed in an oven at about $90^{\circ} \mathrm{C}$ until constant weight is achieved. Due to the high density of kohl samples $\left(\sim 4 \mathrm{~g} / \mathrm{cm}^{3}\right)$ we use pure silica powder $\left(\mathrm{SiO}_{2}, 2.46\right.$ 
$\mathrm{g} / \mathrm{cm}^{3}$ ) to get samples with densities nearly equal the density of reference material. Silica has an appropriate mass attenuation coefficient for gamma rays as shown in Fig. 2. Values of the mass attenuation coefficient $(\mu / \rho)$ of $\mathrm{SiO}_{2}$ are obtained according to the simple summation [4].

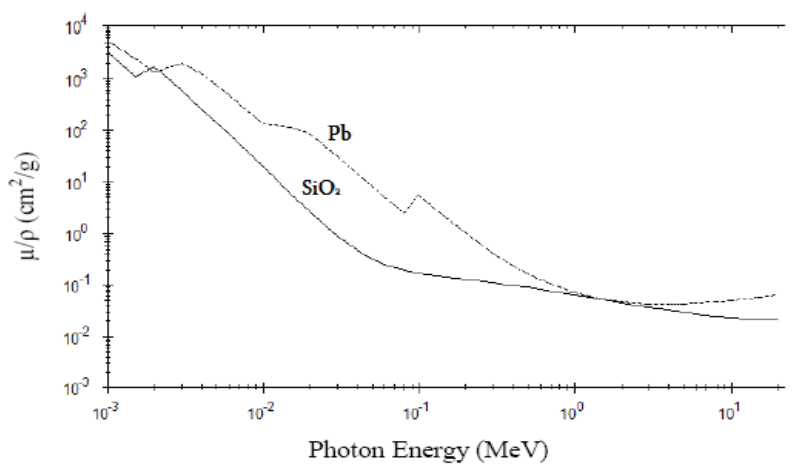

Fig. 2. Mass attenuation coefficient of $\mathrm{SiO}_{2}$ and $\mathrm{Pb}$ as a function of gamma-ray energy.

$$
\mu / \rho=\sum_{i} w_{i}(\mu / \rho)_{i}
$$

where $w_{i}$ is the fraction by weight of the ith atomic constituent, and the $(\mu / \rho)_{i}$ values are taken from [4]. In order to confirm that the use of silica does not affect the rate of self-absorption of the emitted gamma-rays, we used two masses of kohl samples (90 and180 g), and then we added the appropriate amount of silica for each mass to fill $240 \mathrm{ml}$ plastic beakers. Silica and kohl are mixed well to get a homogenous sample which is then sealed for more than 28 days to reach the secular equilibrium between ${ }^{226} \mathrm{Ra}$ and its short lived products.

The radioactivity concentrations are measured using HPGe detector in the Egyptian Nuclear Authority. The same geometry and size are used for both measured and reference material samples. The measurements are collected for 20 to 24 hours [5].

TABLE I: HEAVY ELEMENTS CONCENTRATIONS IN PPM (MEAN \pm RSD\%)

\begin{tabular}{ccccccc}
\hline \hline \multirow{2}{*}{ Sample name } & $\begin{array}{c}\text { Sample } \\
\text { code }\end{array}$ & Country of origin & As & Cd & Hg & Pb \\
\hline Eyeliner & SEL18 & unknown & $3.38 \pm 0.89$ & $<0.0003$ & Nil & $5.33 \pm 1.74$ \\
Mascara & SMM14 & UK & $3.62 \pm 2.72$ & $<0.0003$ & $0.09 \pm 0.50$ & $3.37 \pm 1.67$ \\
Eye shadow & SESR9.1 & China & $<0.008$ & $<0.0003$ & Nil & $35.18 \pm 1.20$ \\
& SESY9. & China & $<0.008$ & $<0.0003$ & $0.04 \pm 2.4$ & $13912.47 \pm 0.33$ \\
& 3 & Unknown & $<0.008$ & $<0.0003$ & $0.12 \pm 0.06$ & $29.12 \pm 1.91$ \\
Kohl powder & SKB31 & India & $<0.008$ & $<0.0003$ & $0.08 \pm 1.10$ & $2771.38 \pm 0.34$ \\
Kohl stone & SKK20 & KSA & $6.23 \pm 1.02$ & $8.00 \pm 0.27$ & Nil & $50666.67 \pm 0.71$ \\
& SKP22 & Pakistan & $13.55 \pm 0.55$ & $39.87 \pm 0.3$ & $0.02 \pm 0.83$ & $547896.44 \pm 1.0$ \\
& & & 4 & & 8 \\
& SKI23 & India & $4.54 \pm 4.51$ & $19.25 \pm 0.0$ & Nil & $564369.31 \pm 0.3$ \\
& & & 3 & & 8 \\
& SKK24 & KSA & $11.23 \pm 1.05$ & $7.56 \pm 0.25$ & $0.06 \pm 0.21$ & $527565.89 \pm 1.0$ \\
& & & & & 6 \\
& SKA1 & KSA & $7.1 \pm 2.8$ & $7.86 \pm 0.53$ & $68.85 \pm 0.00$ & $707033.84 \pm 1.0$ \\
& SKR2 & KSA & $106.12 \pm 0.4$ & $6.39 \pm 0.04$ & $67.9 \pm 0.12$ & $669993.35 \pm 0.6$ \\
& & & 8 & & 6 \\
& SKL3 & Iran & $4.5 \pm 2.62$ & $15.6 \pm 0.07$ & $152.55 \pm 0.0$ & $748344.54 \pm 1.4$ \\
& & & & & 0 \\
\hline \hline
\end{tabular}

\section{RESULTS AND DISCUSSIONS}

\section{A. Elemental Analysis}

Elemental analysis has been applied on the 13 samples using ICP-OES spectrometer. The mean values of heavy elements concentrations are shown in Table I. According to this table the heavy elements concentrations in artificial eyeliner and mascara samples are lower than the allowable levels [1], [2] except As which has some increases (3.38, 3.62 ppm, respectively) more than the allowable level (3 ppm) [1]. The concentrations of $\mathrm{As}, \mathrm{Cd}$ and $\mathrm{Hg}$ are lower than the allowable levels in eye shadow and powdered kohl samples, while the concentrations of $\mathrm{Pb}$ in these samples are higher than the allowable levels. However, these concentrations of $\mathrm{Pb}$ are so low compared with those in kohl stone samples which have concentrations of the four elements higher than the allowable levels (see Table I). R. M. Al-Ashban et al. [6] show that the lead concentrations in imported samples available in KSA range between 0.004 to $53 \%$ (40 to 530000 ppm). Also R. M. Al-Ashban et al. [6] and other earlier studies [7], [8] illustrate the reduction of hemoglobin and the increase of lead level in blood for individuals using kohl compared with those who do not use kohl. Another study [9] indicates the high level of lead in cataract lenses in comparison with clear lenses. R. M. Al-Ashban et al. [6] provide information showing that Kohl mentioned previously in the Arabic and Islamic history is quite different from the currently circulated kohl in Arabic markets by providing considerable evidence to support the suggestion that earlier types of kohl mainly contained antimony sulphide. As antimony sulphide became scarce, it was replaced by lead sulphide and lead oxide [6].

Most Arabic women use kohl at a rate of one to two times daily, with approximately $1 \mathrm{~g}$ each time. Since we cannot estimate the exact amount absorbed into the body from the used kohl, ingested or entered through the tear duct, we roughly assume that about $50 \%$ of the used kohl is absorbed into the body and then calculate the amount of $\mathrm{As}, \mathrm{Cd}, \mathrm{Hg}$ and $\mathrm{Pb}$ absorbed per year by using kohl two times a day. The 
results are shown in Table II. According to this table the values of maximum annual absorbed amount of $\mathrm{As}, \mathrm{Cd}, \mathrm{Hg}$ are $38.73,14.55$ and $55.68 \mathrm{mg}$ respectively, while the maximum value for $\mathrm{Pb}$ is $273145.76 \mathrm{mg}$ and so lead is a main reason to classify kohl as a toxic material [10]. The US-FDA [2] warned not to use the present Kohl as a color additive in any of the products and did not allow the entry of these products to the USA because of kohl contamination by lead. There is no regulation permitting its use in a cosmetic or in any other FDA-regulated product [10].

TABLE II: ANNUAL ABSORPTION OF HEAVY ELEMENTS FROM KOHL AND EYELINER

\begin{tabular}{|c|c|c|c|c|}
\hline \multirow{2}{*}{$\begin{array}{c}\text { Sample } \\
\text { Code }\end{array}$} & \multicolumn{4}{|c|}{ The amount of heavy elements absorbed annually (mg) } \\
\hline & As & $\mathrm{Cd}$ & $\mathrm{Pb}$ & $\mathrm{Hg}$ \\
\hline SEL18 & 1.23 & Nil & 1.95 & Nil \\
\hline SKA17 & Nil & Nil & 1011.55 & 0.03 \\
\hline SKK20 & 2.27 & 2.92 & 18493.33 & Nil \\
\hline SKP22 & 4.95 & 14.55 & 199982.20 & 0.01 \\
\hline SKI23 & 1.66 & 7.03 & 205994.80 & Nil \\
\hline SKK24 & 4.10 & 2.76 & 192561.55 & 0.02 \\
\hline SKA1 & 2.59 & 2.87 & 258067.35 & 25.13 \\
\hline SKR2 & 38.73 & 2.33 & 244547.57 & 24.78 \\
\hline SKL3 & 1.64 & 5.69 & 273145.76 & 55.68 \\
\hline
\end{tabular}

\section{B. Radioactivity Measurements}

The objective of radioactivity measurements is to determine the concentrations of natural radionuclides $\left({ }^{238} \mathrm{U}\right.$, ${ }^{235} \mathrm{U},{ }^{226} \mathrm{Ra},{ }^{232} \mathrm{Th}$, and ${ }^{40} \mathrm{~K}$ ) in kohl stones and to assess the risk from their usage. The IAEA Safety Guide RS-G-1.7 [11] suggests that radiation protection control is not necessary if the radioactivity concentration of naturally occurring radionuclides in a material is below the IAEA Criteria (10 $\mathrm{Bq} / \mathrm{Kg}$ for ${ }^{40} \mathrm{~K}$ and $1 \mathrm{~Bq} / \mathrm{Kg}$ for all other radionuclides of natural origin).

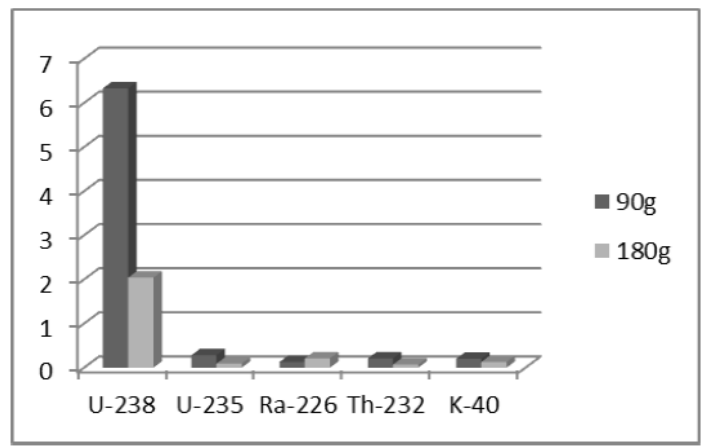

Fig. 3. Activity concentrations $(\mathrm{Bq} / \mathrm{Kg})$ of radionuclides for the two different masses of (SKA1) kohl sample.

Mean values of measured activity concentrations of natural occurring radionuclides in kohl stone samples are listed in Table III. According to this table, the radioactivity concentrations of ${ }^{235} \mathrm{U},{ }^{232} \mathrm{Th}$ and ${ }^{40} \mathrm{~K}$ in kohl samples are lower than the IAEA critical values, while the activity concentrations of ${ }^{238} \mathrm{U}$ and ${ }^{226} \mathrm{Ra}$ have some increases higher than critical values [11]. It is known that the activity concentration is independent on the mass of sample, but during our measurements of activity concentrations in kohl samples, we notice that the nps value (number of counts per second which is directly proportional to activity concentration) in $90 \mathrm{~g} \mathrm{kohl} / \mathrm{sample}$ is larger than its value in $180 \mathrm{~g}$ $\mathrm{kohl} / \mathrm{sample}$ of the same kohl type. This is attributed to the high concentration of $\mathrm{Pb}$ in kohl (see Table I). The amount of $\mathrm{Pb}$ in $180 \mathrm{~g} \mathrm{kohl} / \mathrm{sample}$ is larger than in $90 \mathrm{~g} \mathrm{kohl} / \mathrm{sample}$ which increases the rate of self-absorption of gamma rays before reaching the detector. As a result, some of the gamma emitted from the kohl used to decorate the eye can be absorbed in kohl itself before reaching the eye. For explanation, we show in Fig. 3 and Fig. 4 the activity concentrations in $90 \mathrm{~g}$ and $180 \mathrm{~g}$ of SKA1 and SKR2 samples respectively.

TABLE III: RADIOACTIVITY CONCENTRATIONS (BQ/KG) IN KOHL STONE

\begin{tabular}{cccccc}
\hline $\begin{array}{c}\text { Sample } \\
\text { code }\end{array}$ & ${ }^{238} \mathrm{U}$ & ${ }^{235} \mathrm{U}$ & ${ }^{226} \mathrm{Ra}$ & ${ }^{232} \mathrm{Th}$ & ${ }^{40} \mathrm{~K}$ \\
\hline SKK20 & $6.87 \pm 1.35$ & $0.29 \pm 0.03$ & $1.31 \pm 0.04$ & $0.28 \pm 0.03$ & $4.35 \pm 0.18$ \\
SKP22 & $3.87 \pm 0.60$ & $0.14 \pm 0.02$ & $1.34 \pm 0.04$ & $0.06 \pm 0.01$ & $3.35 \pm 0.12$ \\
SKI23 & $2.49 \pm 0.39$ & $0.11 \pm 0.02$ & $0.16 \pm 0.01$ & $0.60 \pm 0.07$ & $0.85 \pm 0.04$ \\
SKK24 & $4.12 \pm 0.59$ & $0.20 \pm 0.02$ & $1.01 \pm 0.03$ & $0.31 \pm 0.02$ & $3.18 \pm 0.13$ \\
SKA1 & $6.33 \pm 0.27$ & $0.28 \pm 0.03$ & $0.13 \pm 0.01$ & $0.21 \pm 0.02$ & $0.20 \pm 0.01$ \\
SKR2 & $6.49 \pm 1.05$ & $0.29 \pm 0.08$ & $2.61 \pm 0.05$ & $0.25 \pm 0.03$ & $2.15 \pm 0.10$ \\
SKL3 & $1.09 \pm 0.14$ & $0.05 \pm 0.01$ & $0.28 \pm 0.01$ & $0.16 \pm 0.01$ & $0.45 \pm 0.02$ \\
\hline \hline
\end{tabular}

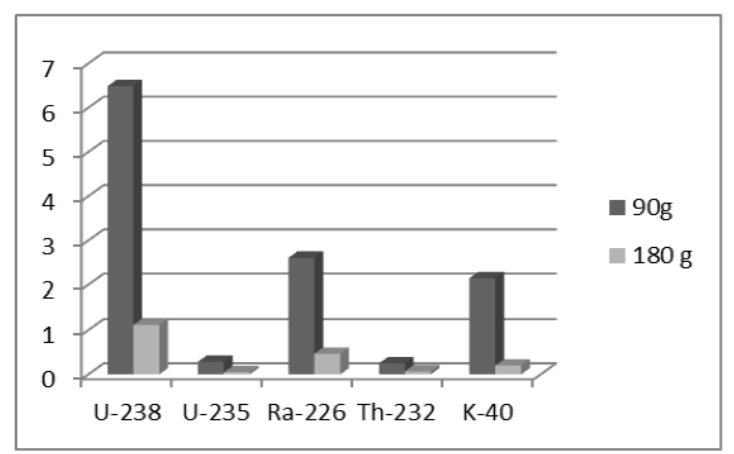

Fig. 4. Activity concentrations $(\mathrm{Bq} / \mathrm{Kg})$ of radionuclides for the two different masses of (SKR2) kohl sample.

\section{THEORETICAL MODEL}

From the previous sections we see that the radioactivity concentrations for the natural radionuclides in the kohl samples are low, which can give the indication that the radiation dose that may affect the eye will be small. However, in Arabic areas some women use kohl two or three times a day, and we think this may lead to an appreciable annual dose affecting the eye, and therefore in this section we try to make a simple model using the MCNP code [12] to estimate how much the annual dose could be.

In our simple model we depict the eye as a sphere with radius $1.25 \mathrm{~cm}$, with the medium inside having the structure of the eye [13]. We then put the radioactive source on the surface of the sphere and calculate the flux through the surface of the lens of the eye. This surface is the intersection of the plane with the sphere shown in Fig. 5. We do these calculations for the natural radionuclides ${ }^{238} \mathrm{U},{ }^{235} \mathrm{U},{ }^{226} \mathrm{Ra},{ }^{232} \mathrm{Th}$ and ${ }^{40} \mathrm{~K}$ for 
seven kohl samples assuming $2 \mathrm{~g}$ of kohl. The results are shown in Table IV in units of $\mu \mathrm{Sv} / \mathrm{yr}$, where the last column shows the total of all the nuclei. In this table, we don't show the relative errors in those numbers because they are very small. As shown in the table, in spite of assuming frequent use of kohl, the dose rates are still small and insignificant. Also from the table we can notice that the largest contribution is from ${ }^{40} \mathrm{~K}$ and then ${ }^{238} \mathrm{U}$.

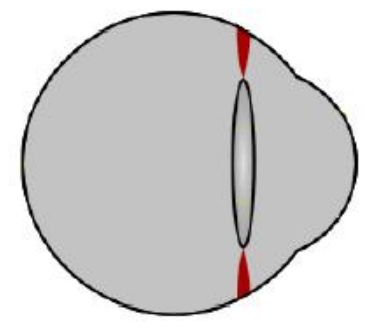

(a)

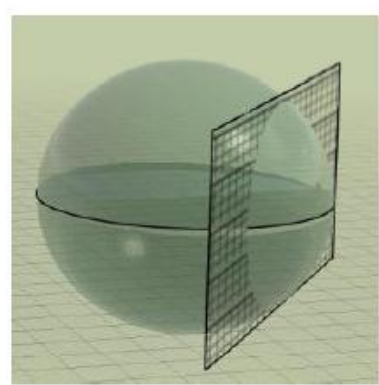

(b)
Fig. 5. The eye lens geometry, (a) real eye lens shape, (b) eye lens shape as we assumed in MCNP simulation.

TABLE IV: ANNUAL DOSE OF THE LENS OF THE EYE FOR NATURAL RADIONUCLIDES DUE TO APPLIED KOHL ( $\mu \mathrm{SV} / \mathrm{YR}$ ) (ANSI/ANS)

\begin{tabular}{ccccccc}
\hline \hline Sample code & ${ }^{238} \mathrm{U}$ & ${ }^{235} \mathrm{U}$ & ${ }^{226} \mathrm{Ra}$ & ${ }^{232} \mathrm{Th}$ & ${ }^{40} \mathrm{~K}$ & Total \\
\hline SKK20 & 0.064 & 0.002 & 0.024 & 0.011 & 0.197 & 0.298 \\
SKP22 & 0.036 & 0.001 & 0.024 & 0.002 & 0.152 & 0.215 \\
SKI23 & 0.023 & 0.001 & 0.003 & 0.024 & 0.039 & 0.090 \\
SKK24 & 0.038 & 0.002 & 0.018 & 0.012 & 0.144 & 0.214 \\
SKA1 & 0.059 & 0.002 & 0.002 & 0.008 & 0.009 & 0.080 \\
SKR2 & 0.060 & 0.002 & 0.048 & 0.010 & 0.097 & 0.217 \\
SKL3 & 0.010 & 0.0004 & 0.005 & 0.006 & 0.020 & 0.0414 \\
SKL3(ICRP) & 0.007 & 0.0003 & 0.004 & 0.006 & 0.019 & 0.0363
\end{tabular}

To convert from the calculated particle flux to human biological dose equivalent rate, we use ANSI/ANS6.1.1-1977 conversion factors (American National Standards Institute, and American Nuclear Society) [14]. This gives the results shown in Table IV. However, it's known that conversion factor sets are subject to changes based on the actions of various national and international organizations due to the reevaluation of existing data and calculations or the availability of new information, and so, for comparison, we use another set of conversion factors, the ICRP-21 (International Commission on Radiological Protection) [14]. We apply it only on the kohl sample SKL3, the results of which are shown in the last line in Table IV but with no significant differences from ANSI/ANS.

\section{CONCLUSION}

After analyzing thirteen samples of eye cosmetics circulating in Arabic markets, we found that some of them are not really safe to use. Some eye shadows contain various concentrations of $\mathrm{Pb}$ which are higher than the allowable levels. The radioactivity concentrations in kohl samples are very low, and so they don't have radiation risk on the eye, as was confirmed by the simple simulation model. However, these kohl samples are contaminated by significant concentrations of heavy elements $\mathrm{As}, \mathrm{Cd}, \mathrm{Hg}$ and $\mathrm{Pb}$. Depending on our assumption that $50 \%$ of the applied amount of kohl is absorbed, the maximum values of the annually absorbed amount of $\mathrm{As}, \mathrm{Cd}, \mathrm{Hg}$ and $\mathrm{Pb}$ from daily applied kohl (2g a day) are 38.73, 14.55, 55.68 and $273145.76 \mathrm{mg}$, respectively. Therefore appreciable amounts of these elements can be absorbed through skin or drop to the mouth and finally move into the blood, kidneys and other organs of the body where they accumulate and cause damage to these organs. It is worth to mention that most of Arabic women prefer to use kohl more than eyeliner to decorate their eyes because of cultural heritage, but according to our results here, we see that it's safer for them to use eyeliner because the heavy elements concentrations in the eyeliner sample are lower than the allowable levels.

\section{ACKNOWLEDGMENT}

We acknowledge all researchers in the High Energy Physics Laboratory at Cairo University. We are also extremely grateful to Prof. Nagdya M. Ibraheim (NUCLEAR SAFETY CENTRE, EAEA) for providing great deal of experience and valuable knowledge.

\section{REFERENCES}

[1] Health Canada, consumer product safety, Guidance on Heavy Metal Impurities in Cosmetics. [Online]. Available: http://www.hc-sc.gc.ca/cps-spc/pubs/indust/heavy_metals-metaux_lo urds/index-eng.php

[2] U. S. Food and Drug Administration. Color additives approved for use in cosmetics. [Online]. Available: http://www.fda.gov/ForIndustry/Color Additives/ColorAdditiveInventories/ucm115641.htm\#table3A

[3] M. T. Diego, A. R. Carol, H. C. Christopher et al., Recommendations of the International Commission on Radiological Protection, ICRP Publication, vol. 60, no. 1-3, 1991.

[4] J. H. Hubbell and S. M. Seltzer, "Tables of X-ray mass attenuation coefficients and mass energy-absorption coefficients from $1 \mathrm{KeV}$ to 20 $\mathrm{MeV}$ for elements $\mathrm{Z}=1$ to 92 and 48," The National Institute of Standards and Technology, 1996.

[5] S. Turhan and L. Gündüz, "Determination of specific activity of ${ }^{226}$ Ra, ${ }^{232} \mathrm{Th}$ and ${ }^{40} \mathrm{~K}$ for assessment of radiation hazards from Turkish pumice samples," J. Environ. Radioact, vol. 99, pp. 332-342, Jan. 2008.

[6] R. M. Al-Ashban, M. Aslam, and A. H. Shah. "Kohl (surma): a toxic traditional eye cosmetic study in Saudi Arabia," Public Health, vol. 118, pp. 292-298, 2004.

[7] M. Aslam, M. A. Healy, S. S. Davis, and A. R. Ali, "Surma and blood lead in children," Lancet, vol. 1, pp. 658-659, 1980.

[8] M. W. Warley, P. Blackledge, and P. O'Gorman, "Lead poisoning from eye cosmetic," BMJ, vol. 13, no. 1, pp. 117, 1968.

[9] N. Shukla, J. K. Moitra, and R. C. Trivedi, "Determination of lead, zinc, potassium, calcium, copper and sodium in human cataract lenses," The Science of the Total Environment, vol. 181, pp. 161-165, 1996.

[10] U. S. Food and Drug Administration, Cosmetics, Kohl, Kajal, Al-Kahal, or Surma: By Any Name, a Source of Lead Poisoning. [Online]. Available: http://www.fda.gov/Cosmetics/ProductandIngredientSafety/ProductIn formation/ucm 137250.htm

[11] Safety Standards, Application of the Concepts of Exclusion Exemption and Clearance, IAEA, Series No. RS-G-1.7. Vienna, 2004.

[12] MCNP, A General Monte Carlo N-Particle Transport Code, version 5, University of California, Los Alamos National Laboratory, 2003.

[13] A. L. Reed, "Medical physics calculations with MCNP: a primer," in Proc. Summer American Nuclear Society Meeting, Boston, MA, 2007, pp. 133-134.

[14] X-5 Monte Carlo Team, Manual of MCNP, vol. 1, Appendix H, pp. 3-7, 2003. 


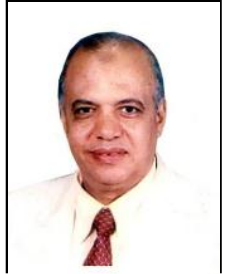

M. M. Sherif was born in Suez, Egypt on January 10, 1946. He got his B.Sc. degree in applied physics in 1968, and then his M.Sc. degree in 1974 and Ph.D. degree in 1977 in experimental nuclear physics from Cairo University, Egypt.

He worked as a teaching assistant of physics from 1975 to 1984 , and as a lecturer of nuclear physics from 1984 to 1992, and then as a professor from 1992 to 2006. He was as a scientific consultant for the Egyptian president, and was the Egyptian coordinator to the European Organization for Nuclear Research (CERN) from 2006 to 2008. Now he works as a professor emeritus of nuclear physics in the faculty of science, Cairo University since 2006. He has many publications like "Slow target associated particle in ${ }^{6} \mathrm{Li}$ - emulsion collisions at $4.5 \mathrm{GeV}$," Modern Physics E2 no. 4, 1993, and "Simulation of muon - induced air showers affecting CMS tracking detector," Physics of particles and nuclei letters vol. 6, no. 3, 2009. His previous interest was in high energy physics, but currently he is interested in environmental physics and radiation protection.

Prof. Sherif was a member of the CMS experiment at CERN. He was a coordinator of nuclear emulsion experiments with JINR-Dubna Russia.

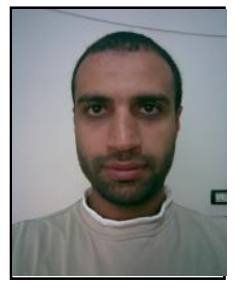

M. Orabi was born in 1978 in Saudi Arabia. He go BSc. degree in 1999 in general physics, and MSc degree in 2003 in theoretical nuclear physics, from Cairo University, Egypt. In 2009 he finished his PhD study in theoretical nuclear physics, at Niigata University, Japan.

He started his career in 2000 as an assistant in the Department of Physics, Faculty of Science, Cairo University. In 2003 he started working as a teaching assistant in the same place, and then as a lecturer from 2009 till now. Some of his publications are "Three-body model of light nuclei with microscopic nonlocal interactions," Physical Review C76, 054003, 2007, and "Removing the forbidden states in a 4-alpha system" Few-Body Systems 51, 2011. His previous interest was theoretical nuclear physics, but recently he is interested in radiation hazards and protection.

Dr. Orabi got an award from Cairo University for his paper "Removing the forbidden states in a 4-alpha system," Few-Body Systems 51, 2011.

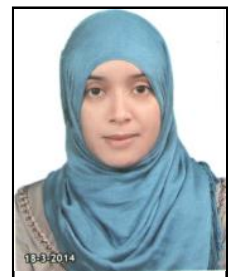

O. R. Abdurahem was born in Al-Khums, Libya on November 14, 1985. She got her B.Sc. degree in physics from Al-Mergib University, Libya. She is an unclear physics M.Sc. student at the Physics Department, Faculty of Science, Cairo University, Egypt.

She worked as a teacher of science at a primary school From 2006 To 2007. Now She works as a teaching assistant since 2009 at the Department of Physics, Faculty Of Science, Al-Mergib University, Libya. 